\title{
Effect of lifestyle intervention on health behaviors, weight and blood glucose level among patients with diabetes mellitus
}

\author{
Salwa A. Mohamed \\ Medical Surgical Nursing Department, Faculty of Nursing, Fayoum University, Egypt \\ Correspondence: Salwa A. Mohamed. Address: Faculty of Nursing, Fayoum University, Fayoum, Egypt. \\ Email: salwaflower@yahoo.com \\ Received: J une 16, 2014 \\ Accepted: September 15, 2014 Online Published: September 29, 2014 \\ DOI : $10.5430 /$ jnep.v4n12p75 \\ URL: http://dx.doi.org/10.5430/jnep.v4n12p75
}

\begin{abstract}
Background: Diabetes in adults is a global health problem and is considered as one of the main threats to human health and its management requires a fundamental change in patient's lifestyle. The aim of this study was assess the effect of lifestyle intervention on health behaviors, weight and blood glucose level among patients with diabetes mellitus.

Methods: A quasi-experimental research design was conducted in outpatient clinics for Diabetes Mellitus at Mansoura University Hospital and Mansoura Health Insurance Hospital, Egypt. The data were collected from 50 adult patients of both sex randomized selected who corresponded to inclusion criteria. A questionnaire (pre and post test) was used to collect data on socio-demographic characteristics, knowledge. Also blood glucose level and weight was taken for physical assessment and health promoting lifestyle profile II.

Results: The results revealed that the majority of study subjects were married females. There was a statistically significant increase in mean of knowledge and health promoting behaviors at immediate and follow up test. Also it was found reduction in body weight and improve of blood glucose levels of studied group.

Conclusion: Health education was effective methods on the studied patients' knowledge scores, decrease weight, improve blood glucose level and health behaviors in the study group. It was recommended that, diabetes patients should be given a written instruction plan for self- management measures of diabetes is better to improve patients outcome.
\end{abstract}

\section{Key words}

Diabetes mellitus, Education, Lifestyle, Body mass index, Blood glucose level, Health behaviors

\section{I ntroduction}

Diabetes in adults is a global health problem. Diabetes mellitus is a disorder of the endocrine system characterized by abnormal fluctuations in blood glucose levels ${ }^{[1]}$, usually related to a defect in insulin production and glucose metabloism. Although its prevalence varies widely between different populations, the rate has generally increased worldwide ${ }^{[2]}$. The total number of people with diabetes is estimated to increase from 171 million in 2000 to 366 million by 2030, with more than $80 \%$ of them living in devloping countries ${ }^{[3-5]}$. Lifestyle and behavioural factors play an important role in the development of diabetes, and lifestyle change is crucial to successful management. However, this is often the most 
challenging aspect of care for both patients and healthcare practitioners ${ }^{[6]}$. Lifestyle education (combined regular exercise, $\&$ healthy dietary) can be considered a cornerstone of prevention as well as management of type 2 diabetes ${ }^{[7-9]}$. Generally, Lifestyle modification, previously termed non pharmacologic therapy, has important roles in diabetes as well as non-diabetes individuals. In diabetes individuals, lifestyle modifications can serve as initial treatment before the start of drug therapy and as an adjunct to medication in persons already on drug therapy ${ }^{[7-9]}$.

Diabetes mellitus is a chronic disease of lifelong duration, and its management requires a fundamental change in the patient's lifestyle ${ }^{[10]}$. It is one of the most psychologically and behaviorally demanding of the chronic medical illness. The outcome of diabetes mellitus treatment is highly dependent on the self-care behavior of the patient. It is estimated that patients are expected to conduct $95 \%$ of their own diabetes mellitus management. They are expected to make multiple lifestyle change simultaneously ${ }^{[11]}$. Life style related risk factors are associated with the development and progression of type 2 diabetes. Risk factors like dietary choices, smoking, alcohol consumption, overweight or obesity and sedentary life style are modifiable. Studies have shown that these factors, if effectively controlled, it can lead to reduction in risk of developing further complications ${ }^{[12-14]}$.

Physical activity or structured exercise training used alone or in combination with diet, insulin injections, or oral hypoglycemic drugs are the foundations of therapy for type 2 diabetes ${ }^{[15,16]}$. Evidence for the benefit of physical activity comes from studies showed that individuals who maintain a physically active lifestyle are less likely to develop insulin resistance, impaired glucose tolerance, or type 2 diabetes ${ }^{[17]}$. The effects of exercise training on glucose control and related physiological parameters have also been extensively studied in patients with type 2 diabetes.

Diet being the cornerstone in the treatment of diabetes mellitus, a need is felt to bring about awareness among diabetic patients, regarding the deleterious effects of an unhealthy diet (high intake of fat, sugar and salt) on patient condition. Therefore, healthy nutrition is the basis for the treatment of type II diabetes. It contributes positively to the maintenance of blood glucose within normal range and minimizes the complications of the disease ${ }^{[18]}$. According to research studies, patients with diabetes mellitus need to be informed about the benefits of appropriate nutritional habits, which are the major key in regulation of blood glucose ${ }^{[19-22]}$.

The nurse plays a pivotal role in helping patients to learn or relearn lifestyle practices, as focusing on the patient's response to health and illnesses rather than on the disease itself ${ }^{[23]}$. Nurses can prevent diabetes complications in patients by providing diabetes education to newly diagnosed patients, creating a multidisciplinary diabetic control regimen with the patient, nutritionist, and diabetes educator, and calling patients bimonthly to check upon patients' compliance with diabetes control regimen ${ }^{[24]}$. As well, McGregor et al. ${ }^{[25]}$ stated that nurses are in a position to implement exercise and diet programs that contribute to the achievement of prevention of secondary complications and the restoration of physical and psychological health of patients ${ }^{[26]}$.

\subsection{Significance of the study}

Diabetes is one of the most costly and burdensome chronic disease, increasing tends to be an epidemic problem throughout the world. Research has vastly improved the diagnosis and management of diabetes mellitus, but as yet no cure has been found ${ }^{[26]}$. For these reasons, there was an urgent need to conduct this study to provide health care providers with a structured intervention program that acts as a starting point to institute measures that directly improve lifestyle pattern to a higher rate and improve physical function for patients with diabetes and consequently reduce complications of diabetes. There is strong evidence that exercise and diet therapy only or in combination with pharmacological therapies is more safe and effective than the usual care. It is also hoped the data that achieved by this study might be of helpful for nurses in planning and implementing of such intervention that improve clinical outcome and health promotion behaviors.

\subsection{Aim of the study}

The present study aimed to assess the effect of lifestyle intervention on health behaviors, weight and blood glucose level among patients with diabetes mellitus. 


\subsection{Research hypothesis}

It is hypothesized that the lifestyle intervention will have a positive effect on health behaviors, weight reduction and blood glucose control of patients with diabetes 2 Material and methods.

\section{Method}

\subsection{Research design}

A quasi-experimental design was utilized in the study.

\subsection{Study settings}

The study was carried out in the Outpatient Clinic of Diabetes Mellitus at Main Mansoura University Hospital and Mansoura Health Insurance Hospital, Egypt.

\subsection{Subjects}

The subjects of the present study were selected as a convenience sampling. They consisted of 50 patients with diabetes, the following inclusion criteria were included: age ranged between 18 and 60 years, sexes (male and female), having confirmed diagnosis of diabetes mellitus for at least six months, able to communicate, also the patients suffering from diabetic complications and attended to previous diabetes education were excluded.

\subsection{Tools for data collection}

Data of this study were collected using the following tools.

\subsubsection{Structured interview questionnaire}

It was designed by the researcher after reviewing the relevant literature. It included two parts: The first part: Socio-demographic data, namely: age, sex, marital status, etc. The second part deals with medical background data such as, diagnosis, past medical / surgical history, height, weight, blood glucose level etc.

\subsubsection{Diabetes knowledge assessment sheet}

This tool was developed by the researcher based on literature review ${ }^{[27-30]}$. It includes patients' knowledge regarding his/her understanding to nature of the disease (definition, types, normal values, diabetes medications, foot care, complications etc.) and healthy behaviors and lifestyle patterns related to diabetes mellitus control namely healthy diet, physical exercise and its benefits, self monitoring blood glucose level, weight monitoring and periodic medical follow up. Each question had a group of answer points, each correct answer had two grades, incomplete answer had one grade, while no answer or did not know was scored zero. The scores obtained for each set of questions was summed up to get the total scores for patient's knowledge. The questionnaires were used after teaching sessions to obtain comparable means of knowledge level.

\subsubsection{Physical assessment sheet}

Designed by the researcher based on review of literature that includes two parts:

a. Measurement of blood glucose control about fasting glucose, and postprandial glucose for estimated glucose concentration.

b. Body mass index (BMI) - an index calculated by a ratio of height in meters to weight in kilograms and used as a measure of obesity ${ }^{[31]}$. Both height and weight were measured without shoes. Weight was measured without accessories, i.e., wallet, keys, mobile phone. 


\subsubsection{Health promoting lifestyle profile II}

Health promoting lifestyle profile II (HPLP II) developed by Walker, Sechrist \& Peder ${ }^{[32]}$. It consists of 52 items, designed to measures health behaviors: Health responsibility ( 9 items), physical activity ( 8 items), nutrition (9 items), spiritual growth (9 items), interpersonal relations (9 items), and stress management ( 8 items). It uses a 4- point rating scale, ranging from 1 (never), 2 (sometimes), 3 (often), and 4 (routinely), which is attached to each statement. Possible scores range from 52 to 208, higher scores indicate better health promotion lifestyle. The test - retest reliability coefficient for the total HPLPII was 88.5. This scale was chosen because of the easy administration and being comprehensive. This tool requires approximately 10 - 15 minutes for completing.

\subsection{Human rights and ethical consideration}

Permission to conduct this study was obtained from the hospitals authorities. The researcher approached patients individually at diabetes outpatient clinic, explaining the purpose of the study, and the importance of intervention in diabetes and then an informed consent was obtained from participants who accepted to participate in the study. The researcher emphasized that participation in the study is entirely voluntary and withdrawal from the study would not affect the care provided, and Confidentiality was maintained by keeping privacy of all participants' information.

\subsection{Validity and reliability}

The developed questionnaires tools were reviewed by 6 panels of experts' medical and nursing field in order to ensure content comprehensiveness, clarity, relevance, and applicability. The test-retest reliability showed a value of 0.87 . The questionnaires were translated from English into Arabic to help the patient understand them.

\subsection{Pilot study}

A pilot study was carried out on ten percent from the total sample size (five patients) to test the feasibility and clarity of the used tools; modifications were done based on the results. Subjects included in the pilot study were excluded from the main study sample.

\subsection{Procedure}

Official written permissions to conduct this study were obtained from the head of outpatient diabetic clinics. Subjects who met the criteria for inclusion and exclusion were approached by the investigator. At that time, the purpose and nature of the study were explained.

This study was conducted according to the following steps: 1st step: Designing the program to be implemented through review of related literature and research results regarding the lifestyle intervention program. It was written in a simple Arabic language and supplemented by photos and illustrations to help the patient understanding of the content.

Also, study tools were tested for content validity by a jury of 6 experts in nursing and medical fields were sought to ensure content comprehensiveness, clarity, relevance and applicability. 2nd step; the researcher met with the selected patients from previous settings. At the initial visit, data were collected on sociodemographic data pertinent to age, sex, education...etc. Also pre test disease related information, physical assessment sheet and health behaviors were assessed for each subjects before exposure to the lifestyle modification. Data were collected during 7 months from April 2012 to Oct. 2012. 3rd step: The education program was given to selected diabetics. The subjects of the study were divided into small groups 5 to 6 patients. The study subjects were exposed to lifestyle intervention activities which are 8 consecutive sessions over four weeks ( 4 session theory \& 4 sessions practical). Each session lasted from 30 to 45 minutes. The first two sessions were designed to equipped subjects with necessary basic information related to diabetes mellitus, one session about healthy diet, one sessions about physical activity (such as walking and using upstairs and ROM exercise) and duration for physical activity occur at least 30 minutes/3 days weekly, also one session about self monitoring blood glucose level, session about weight monitoring and another session about coping with stress and spiritual growth. 
Teaching methods included lectures taught by the instructor, group discussions on individual experiences, demonstrations, and real objects.

All patients in the study group received printed materials with guidelines after each session. The program was implemented according to subjects' physical and mental readiness. Interviewing the study subjects was carried out at the Out patient's clinic, where they were waiting for measuring blood glucose level and blood pressure. During the classes, patients were encouraged to ask questions interject their own experiences and receive feedback from patients and family. 4th step: subjects were approached by the investigator to assess disease related information, self-care and health behaviors after finishing the lifestyle modification program twice: once immediately after finishing the program and three months to evaluate effectiveness of the program on body weight, blood glucose level and health behaviors. These tool requires approximately 30 - 45 minutes for completing.

\subsection{Statistical analysis}

Data were categorized, tabulated, analyzed and data entry was performed using SPSS software; version 18 Inc. Descriptive statistics were presented as frequency, percentage, mean, standard deviation and paired student $t$-test, correlation coefficient to test statistical significance of some variables and test effectiveness of the program. $P$-value $<0.05$ indicates significant results.

\section{Results}

Figure 1 shows distribution of gender subjects in study sample. This figure indicates that more than half of the sample $(60 \%)$ was male and nearly two- fifths of the sample was female (40\%).

Figure 2 displays level of education. Half of the sample (50\%) were reading and writing and secondary education were prevailing among $30 \%$ of the study group. While (10\%) of sample were illiterate.

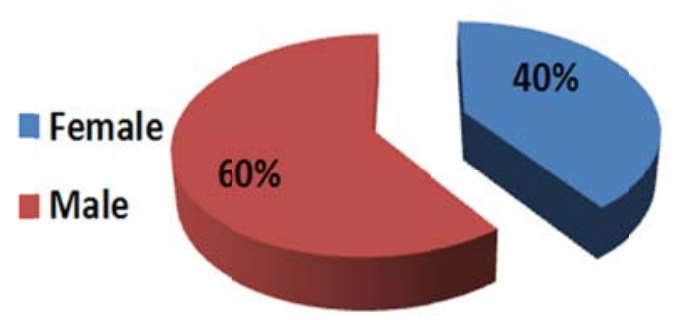

Figure 1. Percentage of distribution of studied sample in relation to gender

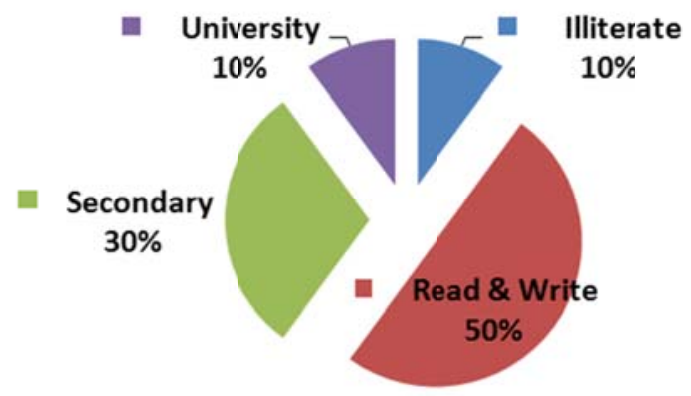

Figure 2. Distribution of the studied groups by level of education

Table 1 shows the most of sample (74.0\%) were 35 years old or more. The majority of the studied subjects (70\%) were married and most of them (94\%) were living with family, (16\%) were employees. As regards monthly income, $(62.0 \%)$ had monthly income ranged from 500 to less than 1000 pound. More three fifths of patients $(62.0 \%)$ lived in rural areas.

Table 2 shows that the total score knowledge of subjects' pre and post implementation of the intervention program. It appears that, the mean total knowledge increased significantly after implementing of program at post and follow up. There are statistically significant at $(p<0.05)$. 
Table 1. Description of sample in relation to socio-demographic characteristics

\begin{tabular}{|c|c|c|}
\hline Patients' Characteristics & No. & $\%$ \\
\hline \multicolumn{3}{|l|}{ Age (in years) } \\
\hline$<25 \mathrm{y}$ & 3 & 6.0 \\
\hline $25-$ & 10 & 20.0 \\
\hline $35-$ & 17 & 34.0 \\
\hline $45+$ & 20 & 40.0 \\
\hline \multicolumn{3}{|l|}{ Marital status } \\
\hline Single & 0 & 0.0 \\
\hline Married & 35 & 70.0 \\
\hline Divorced & 2 & 4.0 \\
\hline Widowed & 13 & 26.0 \\
\hline \multicolumn{3}{|l|}{ Occupation } \\
\hline Worker & 20 & 40.0 \\
\hline Employed & 8 & 16.0 \\
\hline Housewife & 15 & 30.0 \\
\hline Retired & 7 & 14.0 \\
\hline \multicolumn{3}{|l|}{ Living system } \\
\hline Living with family & 47 & 94.0 \\
\hline Living alone & 3 & 6.0 \\
\hline Living with others & 0 & 0.0 \\
\hline \multicolumn{3}{|l|}{ Residence } \\
\hline Urban & 19 & 38.0 \\
\hline Rural & 31 & 62.0 \\
\hline \multicolumn{3}{|l|}{ Monthly income } \\
\hline $500-$ & 31 & 62.0 \\
\hline $1000-$ & 15 & 30.0 \\
\hline $1500-$ & 4 & 8.0 \\
\hline
\end{tabular}

Table 2. Mean score of diabetics knowledge in pre, post test participation in the intervention program implementation (n $=50)$

\begin{tabular}{llll}
\hline Items & Pre Program & Post program & Follow up \\
\hline $\bar{x} \pm$ S.D & $18.49 \pm 3.57$ & $49.16 \pm 4.318$ & $35.67 \pm 2.324$ \\
$\begin{array}{l}\text { Paired t 1 } \\
\text { Pre \& post }\end{array}$ & $7.315 \& p<.05$ & & \\
$\begin{array}{l}\text { Paired t 2 } \\
\text { Pre \&follow }\end{array}$ & $6.217 \& p<.05$ & & \\
$\begin{array}{l}\text { Paired t 3 } \\
\text { Post \&follow }\end{array}$ & $3.315 \& p<.05$ & & \\
\hline
\end{tabular}

Table 3 describes the frequency distribution of the studies group according to walking and physical activities as a helpful exercise in pre- post and follow up participation in the program. It indicates that there is an increase in percentage of subjects walking daily from (18.0) in pre participation to (76.0) post participation in the intervention program. There is a significant statistical relation between pre-test, post-test and follow up frequently per week of physical activity $(p<.05)$. 
Table 3. Frequency distribution of the studied group according to walking and physical activities as a helpful exercises in pre post and follow up participation in the program.

\begin{tabular}{lll}
\hline Walk \& physical activity & No & $\%$ \\
\hline Pre program & 9 & 18.0 \\
Post program & 41 & 82.0 \\
Follow up & 32 & 64.0 \\
Pre\& post & $7.142 \& p<.05$ & \\
Pre \& follow & $5.183 \& p<.05$ & \\
Post \& follow & $3.482 \& p<.05$ & \\
\hline
\end{tabular}

Table 4 reveals that there a significant statistical difference is found between patients mean score of body mass index (79.66) in pre participation to (71.68) post participation in the intervention. Regarding blood glucose level, there are a statistically significant difference is found between subjects' mean scores of blood glucose level (240) in pre participation and (165) after participation. There is a statistical significance between pre- test and post- test and follow up test $(p<.05)$.

Table 4. Changes in physical and metabolic characteristics during pre and post intervention of program

\begin{tabular}{lllll}
\hline \multirow{2}{*}{ Action } & Pre program & Post program & Follow up \\
\cline { 2 - 5 } & Mean \pm SD & Mean \pm SD & Mean \pm SD & $74.65 \pm 13.44$ \\
\hline Body weight $(\mathrm{kg})$ & $79.66 \pm 16.19$ & $71.68 \pm 15.24$ & $28.23 \pm 482$ & $<.05$ \\
BMI $(\mathrm{kg} / \mathrm{m} 2)$. & $30.01 \pm 543$ & $29.10 \pm 412$ & $175 \pm 13.51$ & $<.05$ \\
Blood glucose level & $240 \pm 15.14$ & $165 \pm 12.81$ & 05 \\
\hline
\end{tabular}

Table 5 describes that there is an increase in the mean scores of the subjects total health behaviors from (120.55) in pre participation to (155.98) post participation in the program. There is a statistical significance between pre- test and post- test and follow up test $(p<.05)$.

Table 5. Mean scores of health promoting lifestyle profile of the study pre, post and follow up program implementation

\begin{tabular}{llll}
\hline \multirow{2}{*}{ Items } & Pre program & Post program & Follow up \\
\cline { 2 - 4 } & Mean \pm SD & Mean \pm SD & Mean \pm SD \\
\hline THPLP & $120.55 \pm 8.52$ & $155.68 \pm 12.6$ & $136.37 \pm 11.26$ \\
Pre\& post & $7.142 \& p<.05$ & & \\
Pre \& follow up & $9.987 \& p<.05$ & & \\
Post \& follow up & $8.98 \& p<.05$ & & \\
\hline
\end{tabular}

(*) Statistically significant at $p<.05$; THPLP: total health promotion lifestyle

Figure 3 shows that the health promotion lifestyle practice improvement after participation in lifestyle intervention program.

Figure 3. Change of health promotion lifestyle practice at two point assessment of participation of program

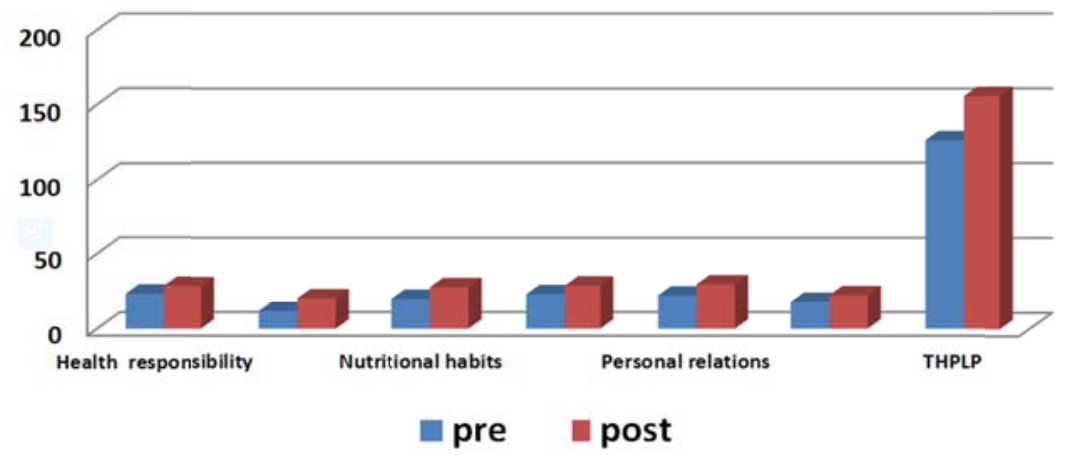


Table 6 shows that correlation found between the total knowledge and practice score with body weight and blood glucose levels pre and post the implementation of the participation program $(p<.05)$.

Table 6. Correlations between body weight and blood glucose level and patients knowledge and practice pre, post and follow up the implementation program

\begin{tabular}{|c|c|c|c|c|c|c|c|c|c|c|c|c|}
\hline \multirow{3}{*}{ Items } & \multicolumn{6}{|c|}{ Body weight } & \multicolumn{6}{|c|}{ Blood glucose level } \\
\hline & \multicolumn{2}{|c|}{ Before } & \multicolumn{2}{|c|}{ After } & \multicolumn{2}{|c|}{ Follow up } & \multicolumn{2}{|c|}{ Before } & \multicolumn{2}{|c|}{ After } & \multicolumn{2}{|c|}{ Follow up } \\
\hline & $\boldsymbol{R}$ & $\boldsymbol{P}$ & $\boldsymbol{R}$ & $p$ & $r$ & $p$ & $r$ & $\boldsymbol{P}$ & $r$ & $\boldsymbol{P}$ & $\boldsymbol{R}$ & $p$ \\
\hline Total knowledge score & \multicolumn{2}{|c|}{$0.692(<.05)$} & \multicolumn{2}{|c|}{$0.481(<.05)$} & \multicolumn{2}{|c|}{$0.561(<.05)$} & \multicolumn{2}{|c|}{$0.238(<.05)$} & \multicolumn{2}{|c|}{$0.515(<.05)$} & \multicolumn{2}{|c|}{$0.131(<.05)$} \\
\hline Total practice score & \multicolumn{2}{|c|}{$2.692(<.05)$} & \multicolumn{2}{|c|}{$0.491(<.05)$} & \multicolumn{2}{|c|}{$1.5861(<.05)$} & \multicolumn{2}{|c|}{$0.237(<.05)$} & \multicolumn{2}{|c|}{$2.513(<.05)$} & \multicolumn{2}{|c|}{$1.130(<.05)$} \\
\hline
\end{tabular}

Table 7 shows that there is a significant correlation between age and $\operatorname{diet}(r=0.512, p=.001)$, which means that older patients tend to have little information about diet than younger patients. There is a significant correlation between educational level and exercise and diet management $(r=0.467,0.531$ at $p<.05)$. Also there is a significant correlation between duration of diabetes and diet and exercise $(r=0.513, p<.05)$ which means that living and experience with diabetes is associated with applied diet and exercise programs. In relation to monthly income, there is a significant correlation between monthly income and $\operatorname{diet}(r=-0.379, p<.05)$. Which a means that decrease income is associated not prepared suitable diet for disease. In addition, there are statistically significant correction between mean score of knowledge and total health promotion lifestyle pattern $(t=10.756, p<.05)$. No statistically significant relations were founds between them as regards sex, marital status and occupation status $(p>.05)$.

Table 7. Multivariable relationships between demographic, disease and level of knowledge after participation of program $(\mathrm{n}=50)$

\begin{tabular}{lll}
\hline \multirow{2}{*}{ Variables } & Level of knowledge & \\
\cline { 2 - 3 } & $\boldsymbol{R}$ & $\boldsymbol{P}$ value \\
\hline Age & $0.512-$ & $<.05^{*}$ \\
Sex & 0.234 & $>.05$ \\
Marital status (married) & 0.668 & $>.05$ \\
Education & 0.467 & $<.05^{*}$ \\
Occupation & 0.131 & $>.05$ \\
Duration of diabetes & 0.513 & $<.05^{*}$ \\
Monthly income & $0.379-$ & $<.05^{*}$ \\
$* *$ THPLP & 10.756 & $<.05^{*}$ \\
\hline
\end{tabular}

$(*)$ Statistically significant at $p<.05 ;(* *)$ Health promotion life style

\section{Discussion}

Diabetes mellitus is a chronic disease of lifelong duration and its management requires a fundamental change in patient's lifestyle. Ongoing patient self-care education and support are critical to preventing acute complications and reducing the risk of long-term complications. Patient education is not an addition to treatment, but it is one of the treatment tools that has a great effect on enhancing the diabetic patients own abilities to carry out self-care through providing adequate knowledge changing their attitude, and empowering them with skills that are essential for better control of the disease ${ }^{[33,34]}$.

The current study showed that the majority of the studied patients were male. These findings are inconsistent with Abdo and Mohamed ${ }^{[35]}$ who revealed that the most of participants (63.11\%) were women and (36.89\%) were men. Regarding educational level of the subjects, the current study results revealed that more half of subjects were reading and writing. 
This finding disagreement of Al Shafaee et al. ${ }^{[36]}$ who found that forty six percent of their study sample was up to high school of college level, surprisingly the researcher expected that educational level could affect the performance of subjects in managing their diabetes in term of diet or importance of performing physical activity.

In the present study, almost three quarters of diabetic subjects were 35 years old or more. On the same line the WHO ${ }^{[37]}$ revealed that diabetes mellitus was most common among the peak age between thirty to sixty years. As well, Shah et al. ${ }^{[38]}$ reported that the mean age of diabetic male and female subjects were (55.30 and 51.74). These findings are agreement with the study results of Whiting et $a l^{[39]}$ who emphasized that most people with diabetes in low and middle income countries are between 40 and 60 years old for both sexes.

These findings are also supported by those of Hillier and Pedulla ${ }^{[40]}$ who studied patients with new-onset type 2 diabetes in a health maintenance organization between the years 1996 and 2000 and found that patients were more likely to be female if they had diabetes onset at a younger age $(<45$ years $)$ but were more likely to be male if they had diabetes onset at older age ( $\geq 45$ years). This could be explained as, diabetes mellitus in adults' ages, increasing being the most important risk factor for type 2 diabetes due to physiological changes. Considering social status, the results showed that relatively high percentages of subjects were married and living with family. These findings are in agreement with the study of Minet ${ }^{[41]}$ who concluded that fifteen patients were married or living with a partner and seven living alone.

Regarding knowledge of the studied subjects, the findings of the present study showed that higher scores of diabetes related knowledge after participation in lifestyle intervention program. On the same line a study done by Atak ${ }^{[42]}$ which revealed that the overall knowledge of all patients received the health educational program on variables at the end of the 4 months were significantly improved the mean of knowledge, behavior score, physical health and psychological health. This result is in accordance with Hawthorne et al. ${ }^{[43]}$ who found improvement in knowledge of the intervention groups after application of culturally appropriate health education was revealed.

Regarding nutrition, there was a statistically significant increase in following dietary regimen after implementation of the program compared with practice before program. The researcher concluded that patients need good support and advices to implement healthy practices perfectly through lifestyle modification. This result is in accordance with Steyn et al. ${ }^{[44]}$ and Swift and Boucher ${ }^{[45]}$ who stated that patients with diabetes mellitus need to be informed about the benefits of appropriate nutritional habits, which is the major key in regulation of blood glucose. This approach is also supported by Franz ${ }^{[46]}$ who reported that patients take diet high in cereal fiber and low in fat make improve in blood glucose level which reflects the effect of diet on the blood glucose level.

The current study findings clarified that after implementing of the lifestyle program relatively high percentage of diabetics' patient perform physical activity. These also confirmed a study by Yamanouchi et al. ${ }^{[47]}$ revealed that walking, which can be safely performed and easily incorporated into daily life, can be recommended as an adjunct therapy to diet treatment in obese NIDDM patients, not only for body weight reduction, but also for improvement of insulin sensitivity. Similarly, Ghavami et al. ${ }^{[48]}$ reported some improvements in both fasting blood sugar and body weight. Furthermore, another study had done Egypt by Weheida et al. ${ }^{[49]}$ who reported significant improvement in lipid profile among hypertensive patients at 8 weeks follow walking program for 45 minutes/ 3 days weekly, and justified this improvement by the benefits of walking which increase sense of wellbeing, relieve emotional tension, and raise the level of HDLc.

Our study showed a statistical significant improvement in body weight and blood glucose level from pre program to after the three months program $(p<.05)$. This in line with Englert \& Coworkers ${ }^{[50]}$ shows that $35 \%$ of the diabetes patients were able to reduce their glucose levels below $125 \mathrm{~m} / \mathrm{dl}$. Of these individual, $10 \%$ were even able to reduce them to blow $100 \mathrm{mg} / \mathrm{dl}$, also during the four week of program, the mean weight reeducation was 9 pounds for men and 7 pounds for women. This may be attributed to reeducation in blood glucose were positively related to weight loss the higher the weight loss, the greater the improvement in blood glucose. Mobley ${ }^{[51]}$ observed the benefits of weight loss on cardiovascular mobility and mortality. 
Lifestyle modification is considered the current challenge to control blood glucose. The results of the current study showed that the total and all dimensions of lifestyle patterns show significant improvement in the studied group after participation in program. Frank et al. ${ }^{[52]}$ mentioned that closer adherence to behavioral guidelines could reduce the risk further in both low-risk and high-risk populations for diabetes. Lawrence et al. ${ }^{[53]}$ agreed that population-wide adoption of healthy lifestyles as promoted in the PREMIER interventions should substantially reduce the societal burden of chronic diseases.

Results of the current study documented that there are a negative statistically significant correlation between mean score of knowledge and age of patients was explored in this study where older patients had lower level of knowledge than younger ones. This finding was similar to those obtained by Kame1 et al. ${ }^{[54]}$ who stated that younger patients were likely to be more educated and new sufferers of diabetes and thus were keen to have more knowledge about their disease. Another research study by Russell et al. ${ }^{[55]}$ who noted that there was negative correlation between age and self-care of patients undergoing diabetes mellitus, they might not be able to carry out some tasks, such as exercise, because of lack of sufficient time, especially with presence of physical limitations.

Our study reported a significant positive relationship between the level of knowledge and the educational level. This finding is in agreement with Kamel et al. ${ }^{[54]}$ who found that knowledge related to disease improved with a corresponding increase in the level of education and socioeconomic status and with working. This may be attributed have a greater probability of obtaining knowledge from books / and other sources such as mass media. Also good communicating with the health care team, and they may grasp knowledge correctly status. This result is in line with Agardh et al. ${ }^{[56]}$ who indicated that burden of type 2 diabetes is attributed to lower educational levels in Sweden. These results coincide with those of a study performed by Larsson et al. ${ }^{[57]}$ which stated that diabetic patients in poor quality of life had low educational level.

In addition to, our study finding reported a significant statistically correlation between monthly income and diabetes lifestyle intervention program. This finding was in accordance with that reported by Browen et al. ${ }^{[58]}$ which showed that there is a relationship between annual income and diabetes self-management. Furthermore, lack of self-control over dietary habits and appropriate meal planning may be managed by high income level. This means that, as the monthly income increases, the self-management of diabetes is controlled better. Regarding duration of diabetes, the results of the present study revealed that a statistical correlation was detected between duration of diabetes and acquiring adequate knowledge among the study subjects. This result was in agreement with Adwan and Najjar ${ }^{[59]}$ who emphasized that as income level increases, diabetes self-management becomes better, and the longer the duration of diabetes, the worse is diabetes self-management.

\section{Conclusion and recommendations}

Findings of the present study revealed that, there was highly statistically significant positive change in lifestyle pattern of patients with diabetes regarding knowledge, behavior and improving weight reduction and blood glucose control after participation of the lifestyle education program. Based on the findings of the current study, it is recommended that: All patients with diabetes mellitus should be given instructions to self-care and lifestyle modification and follow-up instructions. Further research is needed to consider the effect of follow up diabetes education on behavior change and clinical outcomes. Replication of this study on a larger sample and in different hospital settings with increasing the duration of treatment is suggested for generalization of results. Also developed illustrated booklet should be available and distributed for each diabetes patient admitted to the hospital.

\section{Limitations of the study}

Limitations of the Study included the following:

1) The study is limited to small sample size. 
2) The assessment of effect of the Health Promoting Lifestyle Profile is limited to one follow up (3 months).

3) The study did not use control group. The investigator had no control over the events that took place between pre-test and post-test.

\section{Acknowledgement}

I express my gratitude and thanks towards all who have directly or indirectly helped me to complete this study and their support in each major step of the study.

\section{References}

[1] Dunning, T. Care of people with diabetes - A manual of nursing practice Melbourne: Blackwell Publishing. 2003. http://dx.doi.org/10.1002/9780470774649

[2] Chang,C.LuF., Yang,Y.C., Wu,T.J., Chen, M.S., Chuang, L.M., \&Tai,T.Y. Epidemiology study of type 2 diabetes in Taiwan. Diabetes Research Clinical Practice. 2000; 50(2): 49-59. http://dx.doi.org/10.1016/S0168-8227(00)00179-0

[3] World Health Organization (WHO). Adherence to long term therapies: Evidence for action. Switzerland: World Health Organization. 2003.

[4] Wild S., Roglic G., Green A., Sicree R, \& King H. Global prevalence of diabetes: Estimates for the year 2000 and projections for 2030. Diabetes Care.2004; 27: 1047-1053. PMid:15111519 http://dx.doi.org/10.2337/diacare.27.5.1047

[5] Shu-Fang, W. Effectiveness of self-management for persons with type 2 diabetes following the implementation of a self-efficacy enhancing intervention program in Taiwan. Published doctorate dissertation, Philosophy of Nursing at Queensland University of Technology. 2007.

[6] Clark, M. Lifestyle self-management in patients with type 2 diabetes. Journal of Diabetes Nursing. 2002; 6(6): $182-188$.

[7] Kosaka K., Noda M., Kuzuya, T. Prevention of type 2 diabetes by lifestyle intervention: A Japanese trial in IGT males. Diabetes Research and Clinical Practice. 2005; 67: 152-162. PMid:15649575 http://dx.doi.org/10.1016/j.diabres.2004.06.010

[8] Yamaoka K., \& Tango T. Efficacy of lifestyle education to prevent type 2 Diabetes: A meta-analysis of randomized controlled trials. Diabetes Care. 2005; 28(11): 2780- 2787. PMid:16249558 http://dx.doi.org/10.2337/diacare.28.11.2780

[9] Lindström J., Ilanne-Parikka P., \& Peltonen, M. Sustained reduction in the incidence of type 2 diabetes by lifestyle intervention: Follow-up of the Finnish Diabetes Prevention Study. Lancet. 2006; 368: 1673-1679. http://dx.doi.org/10.1016/S0140-6736(06)69701-8

[10] Kamel NM, Badawy YA, el-Zeiny NA, Merdan IA. Sociodemographic determinants of management behavior of diabetic patients. Part I. Behaviour of patients in relation to management of their disease. East Mediterr Health J. 1999 Sep; 5(5): 967-973. PMid:10983537

[11] Clarke J, Crawford A, Nash DB. Evaluation of acomprehensive Diabetes disease management program: progress in the struggle for sustained behavior, Disease Management. 2002; 5(2): 77 -86. http://dx.doi.org/10.1089/109350702320229177

[12] Puska P, Salonen JT, Nissinen A, et al. Changes in risk factors for coronary heart disease during 10 years of community intervenhon programme (North Karelia Project). BMJ. 1983; 287: 1840-4. PMid:6423038 http://dx.doi.org/10.1136/bmj.287.6408.1840

[13] Salonen JT, Puska P, Kottke TE, Tuomilehto J, Nissinen A. Decline in mortality from coronary heart disease in Finland from 1969 to 1979. BMJ, 1983; 286: 1857-60. PMid:6407602 http://dx.doi.org/10.1136/bmj.286.6381.1857

[14] Fortmann SP, Flora JA, Winkleby MA, et al. Community intervention trails: Reflections on the Stanfford Five City Project experiment. Am J Epidemiol, 1995; 142: 576-86. PMid:7653465

[15] Meltzer S., Leiter L., Daneman D., Gerstein H.C., Lau D., Ludwig S., et al. Clinical practice guidelines for the management of diabetes in Canada. Can Med Assoc J. 1998; 159(Suppl. 8): S1-S29.

[16] Canadian Diabetes Association. Clinical practice guidelines for the prevention and management of diabetes in Canada. Can J Diab. 2003; 27(2): S1-S152.

[17] Eriksson K.F, \& Lindgarde, F. Prevention of type 2 (non-insulin-dependent) diabetes mellitus by diet and physical exercise: The 6-year Malmo feasibility study. Diabetologia. 1991; 34: 891-898. http://dx.doi.org/10.1007/BF00400196

[18] Polikandrioti M., \& Dokoutsidou, H. The role of exercise and nutrition in type II diabetes mellitus management. Health Science Journal. 2009; 3(4): 216-221.

[19] Swift CS., Boucher JL. Nutrition therapy for the hospitalized patient with diabetes. Endocr Pract.2006; 12 Suppl 3: 61-7. PMid:16905519 http://dx.doi.org/10.4158/EP.12.S3.61 
[20] Steyn NP., Mann J., Bennett PH., Temple N., Zimmet P., Tuomilehto J., et al. Diet, nutrition and the prevention of type 2 diabetes. Public Health Nutr. 2004; 7(1A): 147-65. PMid:14972058 http://dx.doi.org/10.1079/PHN2003586

[21] Franz M.J. Prioritizing diabetes nutrition recommendations based on evidence. Minerva Med. 2004 ; 95(2): 115-23. PMid:15272246

[22] Willett W., Manson J., \& Liu S. Glycemic index, glycemic load, and risk of type 2 diabetes. Am J Clin. Nutr. 2002; 76(1): 274S-80S. PMid:12081851

[23] Rabelo E.R., Aliti, G.B., Domingues, F.B., Ruschel, K.B., and De Oliveira Brun, A. What to teach to Ppatients with heart failure and why: The role of nurse in heart failure clinics. Rev Lat Am Enfermagem J. 2007; 15(1): 165-70. http://dx.doi.org/10.1590/S0104-11692007000100024

[24] Taylor C.B, Miller, N.H, \& Reilly, K.R, et al. Evaluation of a nurse-care management system to improve outcomes in patients with complicated diabetes. Diabetes Care. 2003; 26: 1058-63. http://dx.doi.org/10.2337/diacare.26.4.1058

[25] McGregor A.H., Dore, C.J., Morris, T.P., Morris, S., \& Jamrozik, K. Function after spinal treatment, exercise and rehabilitation (faster): Improving the functional outcome of spinal surgery. Musculoskeletal Disorders. 2010; 11: 17. PMid:20102625 http://dx.doi.org/10.1186/1471-2474-11-17

[26] Peimani M, Tabatabaei -Malazy O, Pajouhi M. Nurses' Role in Diabetes Care; A review. Iranian Journal of Diabetes and Lipid Disorders.2010; 9: 1-9.

[27] Gopalan C., Rama Sastri, B.V., Balasubranium, S.C. Revised and updated by Narsingharao, Deosthale, Y.G, Pant, K.G. Nutritive value of Indian foods. National institute of nutrition, Hyderabad, 1994.

[28] De Feo P., Di Loreto C., Kosaka K., Noda M., Kuzuya T. Prevention of type 2 diabetes by lifestyle intervention: a Japanese trial in IGT males. Diabetes Research and Clinical Practice, 2005; 67: 152-162. PMid:15649575 http://dx.doi.org/10.1016/j.diabres.2004.06.010

[29] Sato Y., Nagasaki M., Kubota M., Uno T., \& Nakai N. Clinical aspects of physical exercise for diabetes/metabolic syndrome. Diabetes Res Clin Pract. 2007; 77(Suppl 1): S87-91. PMid:17498834 http://dx.doi.org/10.1016/j.diabres.2007.01.039

[30] Schwellnus MP, Patel DN, Dreyer M, Whitesman S, Healthy lifestyle interventions in general practice Part 4: Lifestyle and diabetes mellitus . SA Fam Pract 2009, 51(1): 19-25. http://dx.doi.org/10.1080/20786204.2009.10873800

[31] Williams, M.H. Nutrition for fitness and sport. E.Bantell (Ed.). Dubuque, IA:Brown \& Benchmark.1995.

[32] Walker K, Sechrist N, Peder A. The Health Promoting Lifestyle Profile. 1995.

[33] Nicolucci A, Ciccarone E, Consoli A, Di Martino G, La Penna G, Latorre A, et al. Relationship between patient practice-oriented knowledge and metabolic control in intensively treated type 1 diabetic patients: Results of the validation of the Knowledge and Practices Diabetes Questionnaire. Diabetes Nutr. Metab. 2000; 13(5): 276-83. PMid:11105970

[34] American Diabetes Association. Standards of Medical Care in Diabetes. Diabetes Care. 2014; 1(37): S14-S80.

[35] Abdo M N., Mohamed E M. Effectiveness of health education program for type 2 diabetes mellitus patients attending Zagazig University Diabetes Clinic, Egypt. J Eg!ypt Ptrblic Henltlt Assoc. 2010; 85(3,6,4).

[36] Al-Shafaee M.A, Ganguly S.S, Bhargava, K.,\& Duttagupta K.K. Prevalence of metabolic syndrome among prediabetic Omani adults: A preliminary study. Metab Syndr Relat Disord. 2008; 6: 275-9. PMid:19067531 http://dx.doi.org/10.1089/met.2008.0019

[37] World Health Organization (WHO. Diabetes facts: Retrieved November, 30. 2007; Available at: http://www.who.int/mediacentre/factsheet,fs3/2/en/index.html.

[38] Shah A., Bhandary S,. Malik S, Risal, P., \& Koju, R. Waist circumference and waist-hip ratio as predictors of type 2 diabetes mellitus in the Nepalese population of Kavre District. Nepal Med Coll J. 2009; 11(4): 261-267. PMid:20635606

[39] Whiting D.R., Guariguata L., Weil, C., \& Shaw, J. IDF diabetes atlas: Global estimates of the prevalence of diabetes for 2011 and 2030. Diabetes Research and Clinical Practice. 2011; 94(3): 311-321. PMid:22079683 http://dx.doi.org/10.1016/j.diabres.2011.10.029

[40] Hillier T.A. \& Pedula K.L. Characteristics of an adult population with newly diagnosed type 2 diabetes: The relation of obesity and age of onset. Diabetes Care. 2001; 24: 1522: 1527.

[41] Minet R. K. L. Self-Management in Diabetes Care: The importance of self-care management intervention in chronically ill patients diagnosed with diabetes. Published Doctorate, Thesis in Research Science. Faculty of Health Sciences, University of Southern Denmark, Odense. 2010.

[42] Atak N. A pilot project to develop and assess a health education programme for type 2 diabetes mellitus patients. Health Education Journal. 2005; 64(4): 339-46. http://dx.doi.org/10.1177/001789690506400405

[43] Hawthorne K, Robles Y, Cannings-John R, Edwards-Adrian GK. Culturally appropriate health education for type 2 diabetes mellitus in ethnic minority groups. Cochrane Database of Systematic Reviews.2008; issue 3. Art. No.: CD006424. PMid:18646153 
[44] Steyn NP, Mann J., Bennett PH, N Temple N, Zimmet P, Tuomilehto J, et al. Diet, nutrition and the prevention of type 2 diabetes. Public Health Nutrition. 2004; 7(1A): 147-165. PMid:14972058 http://dx.doi.org/10.1079/PHN2003586

[45] Swift CS, Boucher JL. Nutrition therapy for the hospitalized patient with diabetes, Endocr Pract. 2006; $12(3)$ : 61-7. PMid:16905519 http://dx.doi.org/10.4158/EP.12.S3.61

[46] Franz MJ. Prioritizing diabetes nutrition recommendations based on evidence. Minerva Med. 2004; 95(2):115-23. PMid:15272246

[47] Yamanouchi K., Shinozaki T., Chikada K., Nishikawa T., Katsunori, I., Shoji, S., et al. Daily walking combined with diet therapy is a useful means for obese NIDDM patients not only to reduce body weight but also to improve insulin sensitivity. Diabetes care; 18:775-778. PMid:7555502 http://dx.doi.org/10.2337/diacare.18.6.775

[48] Ghavami H, Ahmadi F, Meamarian R, Entezami H. Effects of applying continuous care model on fasting blood glucose \& HgbA1c levels in diabetic patients. Journal of Semnan University of medical sciences. 2004; 6(3): 179-186.

[49] Weheida SM, Ahmed HA, Shehata AE, Shaala SA. Effect of Walking and Breathing Exercise on Controlling Hypertension. Alexandria Nursing Science. 2009; 8(1): 105-33.

[50] Englert S.H., Dieh A H., Greenlaw L R. and Aldana S. The effects of lifestyle modification on glycemic levels and medication intake: The rockfold CHIP. "Public Health » "Primary Care at a Glance - Hot Topics and New Insights", book edited by Oreste Capelli, 2012. ISBN 978-953-51-0539-8.

[51] Mobley CC. Lifestyle interventions for "diabesity": the state of the science. Compend Contin Educ Dent. 2004 ; 25 (3): $207-214$. PMid:15641326

[52] Frank B. Hu, M.D., JoAnn E. Manson, M.D., Meir J. Stampfer, M.D., Graham Colditz, M.D., Simin Liu, M.D., Caren G. Solomon, M.D., and Walter C. Willett, M.D. Diet, Lifestyle, and the Risk of Type 2 Diabetes Mellitus in Women. N Eng1 J Med. 2001; 345: 790-797. PMid:11556298 http://dx.doi.org/10.1056/NEJMoa010492

[53] Lawrence J. Modification on Blood Pressure Control Main Results of the PREMIER Clinical Trial. JAMA. 2003; 289 : 16.

[54] Kame1 NM, Badawy YA, El- Zeiny NA, Merdan IA. Sociodemographic determinants of management behaviour of diabetic patients. Part I. Behaviour of patients in relation to management of their disease. East Mediterr Health J. 1999; 5(5): $967-73$. PMid:10983537

[55] Russell L., Safford M., \& Suh, D. Time requirements for diabetes self-management: Too much for many? The Journal of Family Practice, 2005; 54(1): 52-56. PMid:15623407

[56] Agardh E.E, Sidorchuk A., Hallqvist J., Ljung R., Peterson T .M, and Allebeck P. Burden of type 2 diabetes attributed to lower educational levels in Sweden. Population Health Metrics. 2011; 9: 60. PMid:22176634 http://dx.doi.org/10.1186/1478-7954-9-60

[57] Larsson D., Lager I., Nilsson P.M. Socio-economic characteristics and quality of life in diabetes mellitus - relation to metabolic control. Scandinavian Journal of Public Health. 1999; 27(2): 101-105. PMid:10421717 http://dx.doi.org/10.1177/14034948990270020901

[58] Brown T., Childs B., Funnel, M., Haas, L., Hosey, G, Jensen, B., \& Weiss, M. National standards for diabetes self- management education. Journal of Diabetes Care. 2012; 32(1): S87-S94.

[59] Adwan A. M. \& Najjar, W.Y. The relationship between demographic variables and diabetes self-management in diabetic patients in Amman City/Jordan. Global Journal of Health Science. 2013; 5(2): 213-220. PMid:23445711 http://dx.doi.org/10.5539/gjhs.v5n2p213 